\title{
Amphotericin B as Alternative to Itraconazole in Secondary Prophylaxis of Neurohistoplasmosis in HIV-Positive Patients with Antiretroviral Therapy
}

Jose Luis Puerto Alonso*, F. Tellez, M. Perez, S. Lorenzo-Moncada, D. Miragaya and P. Diaz de Souza

Department of Internal Medicine, Hospital S.A.S. La Linea de la Concepcion, Avda. Menendez Pelayo S/N, 11300 La línea de la Concepcion (Cadiz), Spain

Keywords: Histoplasma; Neurohistoplasmosis; Drug-drug interaction; Itraconazole; Nonnucleoside reverse-transcriptase inhibitors

Histoplasma is a dimorphic pathogenic fungus wich causes human infection worldwide, mainly in ecuatorial countries [1]. In immunocompetent patients the most commun clinical manifestations consist in a lack of symptoms or a self-limited flu-like profile. However, disseminated histoplasmosis, wich represents the $0.05 \%$ of the acute infections, is observed in immunosuppressed patients (most of them HIV infected or treated with immunosuppressive drugs), and the illness manifestations are indistinguishable from tuberculosis. Central nervous system (CNS) involvement is exceptional and affects $5-10 \%$ of patients with disseminated illness and only 26 previous cases of meningitis caused by this microorganism were described in the last decade [2]. The majority of these patients are treated with nonnucleoside reverse-transcriptase inhibitors, and it is necessary to notice that interaction between this drugs and itraconazole (used in the prophylaxis of these infections) exists. Although this drug-drug interaction is really presumed, the international literature review using MEDLINE database and EMBASE (keywords: interaction \pm itraconazole \pm nonnucleoside \pm reverse-transcriptase \pm inhibitors) showed only 3 previous cases [3-5]. It is interesting to report here, because of its rareness, one case of acute meningitis due to Histoplasma, whose treatment and prophylaxis failed initially because of drug-drug interaction between itraconazole and nonnucleoside reverse-transcriptase inhibitors.

A 32-year-old Bolivian man, who lived in Spain for the last three years, with a medical history in his youth of Guillain-Barré syndrome, a doubtful pulmonary tuberculosis, malaria, without sequels, and a recent HIV infection classified as CDC stage C3, whose initial manifestation six months before was a septic shock caused by a disseminated infection due to a filamentous dimorphic fungus identified as Histoplasma (the microorganism grew in bronchial aspirated, blood and bone marrow samples), was admitted into our hospital because of headache, vomiting, walking instability and disrupted speech. He received prophylactic itraconazole oral solution, $200 \mathrm{mg}$ twice a day, and highly-active antiretroviral therapy (HAART) with tenofovir/emtricitabine/efavirenz, with a good virological response and a CD4 cell count around 200. The physical examination revealed a temperature of $38.0^{\circ} \mathrm{C}$, neck stiffness, dysarthria and ataxia. Lumbar puncture showed a clear cerebrospinal fluid (CSF) with a white blood cell count of $110 / \mu \mathrm{l}$ ( $90 \%$ mononuclear), proteins $384 \mathrm{mg} / \mathrm{dl}$, glucose $24 \mathrm{mg} / \mathrm{dl}$ and adenosine deaminase (ADA) $18 \mathrm{U} / \mathrm{l}$. Cultures, bacilloscopies, India ink staining and serology for Treponema $s p$. in CSF were negative. Simple radiologic study of thorax showed fibrotic lesions in both upper pulmonary lobes and residual granulomas. The brain scanner only evidenced cortico-subcortical atrophy. Sputum and blood cultures were finally negative. Meningoencephalitis by mycobacteria was suspected and a treatment with isoniazid, rifampicin, pyrazinamide and ethambutol was initiated. Two weeks later the patient was discharged because of CSF and clinical recovery.

However, two moths later, the patient was admitted again with a similar clinical profile, while the newly obtained CSF showed 100 cells $(90 \%$ mononuclears), glucose $35 \mathrm{mg} / \mathrm{dl}$, proteins $310 \mathrm{mg} / \mathrm{dl}$ and ADA $14 \mathrm{U} / \mathrm{l}$.
Bacilloscopies, Löwenstein-Jensen Culture, PCR for mycobacteria, India ink staining and serology were negative again. Brain scanner and magnetic resonance (with/without gadolinium) were normal. Because of the case severity and the evidence of the previous treatment's failure, we decided to initiate a long term therapy with liposomal amphotericin B (4 mg/ $\mathrm{Kg} / \mathrm{d}$ ) for four weeks, followed by secondary prophilaxis with itraconazole (200 mg twice a day). Subsequent serology tests in CSF for Treponema, Brucella, Borrelia, CMV, EBV, SHV 1 and 2, herpes virus group 6, 7, and 8, Toxoplasma, enterovirus and JC-virus, were negative. Serology tests in blood samples for Tenia solium (IgG), Blastomices (IgG), Coccidiodes and Paracoccidiodes were negative. Antibodies against Hystoplasma capsulatum (IgG) were positive. Plasma PCR for Hystoplasma capsulatum was positive. All these tests were done in the Carlos III National Health Institute, Madrid.

Despite this, two months later the patient had to be readmitted into hospital because of his condition worsened. This time, a long term treatment with liposomal amphotericin B for 16 weeks was decided $(5 \mathrm{mg} / \mathrm{Kg} / \mathrm{d})$. HAART was changed to emtricitabine/tenofovir disoproxil fumarate plus lopinavir/ritonavir because of discordant response and suspected drugdrug interaction between itraconazole and efavirenz. Excellent clinical and analytic improvements were observed and weekly secondary prophylaxis with liposomal amphotericin B was kept $(5 \mathrm{mg} / \mathrm{Kg} /)$ for a year, because of the impossiblility of checking itraconazole levels in our laboratory. For that reason we did not obtain urine histoplasma antigen either for monitoring therapeutic effectiveness, as guides recommend [6]. Lumbar puncture at the end of the treatment and after one year with prophylaxis with amphotericin B were normal. After a 2-year follow-up without prophylaxis, the patient is asymptomatic with a CD4 cell count around 350/ml.

The diagnosis of neurohistoplasmosis is difficult, and it is stablished through the clinical evidence of NCS involvement and one of these: a) CSF antibodies; b) CSF antigen; c) culture isolation in CSF or hystologic demonstration in the brain or meningal tissues. However, the diagnosis of chronic isolated CNS infection can be complex, because the serological tests, the direct observation and the CSF cultures are usually negative [2]. The better therapy for neurohistoplasmosis is unknown [2]. The few suggested guidelines are based on some outcomes CNS histoplasmosis described in the literature and in our own experience [1-2]. Treatment

*Corresponding author: Jose Luis Puerto Alonso, Avda Mexico, Parque Stadium, Bque 6, 11405 Jerez de la frontera (Cadiz), Spain, Tel: +34956088984; E-mail: puertoalonso@hotmail.com

Received February 24, 2011; Accepted March 25, 2011; Published March 26, 2011

Citation: Alonso JLP, Tellez F, Perez M, Moncada SL, Miragaya D, et al. (2011) Amphotericin B as Alternative to Itraconazole in Secondary Prophylaxis of Neurohistoplasmosis in HIV-Positive Patients with Antiretroviral Therapy. J AIDS Clinic Res 2:121. doi:10.4172/2155-6113.1000121

Copyright: (C) 2011 Alonso JLP, et al. This is an open-access article distributed under the terms of the Creative Commons Attribution License, which permits unrestricted use, distribution, and reproduction in any medium, provided the original author and source are credited. 
Citation: Alonso JLP, Tellez F, Perez M, Moncada SL, Miragaya D, et al. (2011) Amphotericin B as Alternative to Itraconazole in Secondary Prophylaxis of Neurohistoplasmosis in HIV-Positive Patients with Antiretroviral Therapy. J AIDS Clinic Res 2:121. doi:10.4172/2155-6113.1000121

Page 2 of 2

must be prolonged, and the most optimal is liposomal amphotericin $\mathrm{B}$ at $5 \mathrm{mg} / \mathrm{Kg} /$ day for $6-16$ weeks. Therapy could continue with itraconazole (200 mg 2-3 times/day), until at least one year of treatment is completed. Our case is an example of secondary prohylaxis with liposomal amphotericin B as an alternative to itraconazole, wich could be useful if it is not possible to check itraconazole levels or to obtain urine histoplasma antigen [7]. In case of severe immunodeficiency lifelong treatment could be necessary. On the other hand, patients with a good immune response (CD4 cell count higher than 150 cells $/ \mathrm{mm} 3$ could stop the therapy [8].

However, it is necessary to remember that itraconazole is mainly metabolized to hydroxyitraconazole by the cytochrome P450 34A enzyme [9]. This enzyme takes part in the nonnucleoside reversetranscriptase inhibitors. It is also necessary to remember that ritonavir is a CYP3A4 inhibitor. Therefore, if protease inhibitors are used, itraonazole levels could be increased, and to check itraconazole levels is recommended. Some works have demonstrated that when we administer efavirenz and itraconazole together, the bioavailability of itraconazole is lower [3,9]. Consequently we should remember that prophylaxis of neurohistoplasmosis can fail because of drug-drug interaction between itraconazole and nonnucleoside reverse-transcriptase inhibitors and ritonavir. If it is not possible to check itraconazole levels, prophylaxis with amphotericin B is useful.

\section{References}

1. Wheat LJ, Batteiger BE, Sathapatayavongs B (1990) Histoplasma capsulatum infections of the central nerovous system: a clinical review. Medicine 69: 244-460.

2. Wheat LJ, Musial CE, Jenny-Avital E (2005) Diagnosis and management of central nervous system histoplasmosis. Clin Infect Dis 40: 844-852.

3. Andrade RA, Evans RT, Hamill RJ, Zerai T, Giordano TP (2009) Clinical evidence of interaction between itraconazole and nonnucleoside reverse transcriptase inhibitors in HIV-infected patients with disseminated histoplasmosis. Ann Pharmacother 43: 908-913.

4. Koo HL, Hamill RJ, Andrade RA (2007) Drug-drug interaction between itraconazole and efavirenz in a patient with AIDS and disseminated histoplasmosis. Clin Infect Dis 45: 77-79.

5. Huet E, Hadji C, Hulin A, Botterel F, Bretagnes S, et al (2008) Therapeutic monitoring is necessary for the association itraconazole efavirenz in patients with AIDS and disseminated histoplasmosis. AIDS 22: 1885-1886.

6. Wheat LJ, Freidedd AG, Leiman MB, Baddley JW, McKinsey DS, et al (2007) Clinical Practice Guidelines for the Management of Patients with Histoplasmosis: 2007 Update by the Infectious Diseases Society of America. Clin Infect Dis 45: 807-825.

7. Guias para el tratamiento de las enfermedades infecciosas (2004) OPS Washington DC.

8. Goldman M, Zackin R, Fichtembaum CJ, Skiest DJ, Koletar SL, et al (2004) Safety of discontinuation of maintenancy therapy for disseminated histoplasmosis after immunologic response to antirretroviral therapy. Clin Infect Dis 38: $1485-1489$.

9. De beule K, Van gestel J (2001) Pharmacology of itraconazole. Drugs 61: 27-37. 